\title{
MAIS UMA NOVA TEORIA SOBRE O NOVO? ${ }^{1}$ ENTREVISTA: OSCAR CALAVIA SÁEZ ${ }^{2}$ \\ Por Jean Segata ${ }^{3}$
}

\section{MORE A NEW THEORY ABOUT THE NEW? INTERVIEW: OSCAR CALAVIA SÁEZ}

\author{
By Jean Segata
}

\section{APRESENTAÇÃO}

Nesta entrevista com Jean Segata, Oscar Calavia Sáez aborda dois aspectos que são um incômodo na Teoria Ator-Rede - TAR, ou para melhor dizer, na sua recepção nos meios acadêmicos. Isso implica pensar que quase tudo o que será dito aqui não diz respeito às relações entre a TAR e um "logo aí" genérico. Conforme provoca Saez, essa "não é uma discussão de seus méritos e/ou deméritos na hora de tratar com o mundo, mas uma reflexão sobre suas utilidades e inutilidades numa parcela desse mundo, que é o espaço acadêmico. Essa parcela, aliás, tem crescido o suficiente, de modo que tratar dela não pode mais ser visto como autocontemplação. O campo acadêmico não tem mais, na atualidade, a forma de uma elite, de um modo ou de outro articulada com outros dados sociais, pois está maciçamente imbricado em movimentos e burocracias. Se a TAR tem insistido em eliminar a barreira entre a posição do observador e o que ele observa, deve-se, entre outros fatores, a um mandado demográfico".

\footnotetext{
${ }^{1} \mathrm{O}$ conteúdo da entrevista, concedida por e-mail, segundo o próprio entrevistado, "sintetiza várias conversas sobre a TAR e, em particular, sobre o livro-manifesto de Bruno Latour Reassembling the Social, em contextos relativamente informais: mesas-redondas, seminários e aulas". Em meio a outras tantas socitações em curso, o formato entrevista foi a melhor opção não tendo tempo para se dedicar a uma reorganização com as devidas referências a todos os dados aduzidos, possibilitando assim sua valiosa contribuição para a Revista Inter-Legere e seu público.

${ }^{2}$ Professor titular, docente da Universidade Federal de Santa Catarina (Programa de Pós-Graduação em Antropologia Social) e da Universidad Complutense de Madrid, nesta graduou-se em História e Geografia. É mestre em Antropologia Social pela Universidade Estadual de Campinas, doutor em Antropologia Social pela Universidade de São Paulo e pós-doutor pelo Centre National de la Recherche Scientifique (CNRS), deste é pesquisador associado. Membro correspondente da Société des Americanistes e do corpo editorial do Journal de la Société des Américanistes. Bolsista de Produtividades do CNPq. Autor de livros premiados pela Academia Espanhola de Letras.

${ }^{3}$ Organizador do Dossiê Teoria Ator Rede para este número 19 da Revista Inter-Legere. Professor da Universidade Federal do Rio Grande do Sul (Programa de Pós-Graduação em Antropologia Social).
} 


\section{ENTREVISTA}

Jean Segata: Nos últimos anos, temos assistido a uma profusão de debates nas Ciências Sociais em torno da Teoria Ator-Rede. Com ela, o nome de Bruno Latour tem circulado como uma esperança de novos ares teórico-metodológicos na disciplina. Como você tem pensado esse movimento?

Oscar Calavia Sáez: O primeiro dos aspectos que me incomodam corresponde à noção de que a TAR é uma teoria exigida por fenômenos novos, sobretudo aqueles abordados pelos novos estudos de ciência e tecnologia, ou aqueles que os emulam em combinações novas de objetos, lugares, sujeitos, por exemplo: um acelerador de partículas, as marmotas que se proliferam no solo onde o acelerador está instalado e a cafeína que consomem em abundância os seus operadores. Para céticos que ouvem falar pela primeira vez dos seus produtos, a TAR pode parecer uma teoria do oximoro em série, evocando aquele "encontro casual entre uma máquina de costura e um guarda-chuva numa mesa de dissecção" de Lautreamont. Nesse sentido, o que o surrealismo tomou como efeito estético da livre associação, no caso da TAR, é apenas o início do caminho que leva a reconhecer conexões que as teorias anteriores desconsideravam e que, em algum dia, poderão ser tão clássicas quanto as que já se estabeleceram entre o capitalismo, a máquina a vapor e o calvinismo; ou entre o açúcar, a domesticação das classes operárias e a Guerra do Ópio.

Teorias sociais clássicas tratam de objetos sociais clássicos e, embora se sintam perfeitamente capazes de abordar objetos novos, de praxe, fazem isso reduzindo-os. Alguma coisa parece ter se perdido no caminho quando um movimento articulado através de redes sociais na internet é interpretado aludindo à sociedade e às classes em que se divide, de modo que essa retórica consistente em martelar com o adjetivo "novo" não deixa de ter sua justificação.

Em face disso, questionamos: o que acontece com temas igualmente clássicos que durante decênios foram descritos no quadro dessas teorias sociais clássicas? O que acontece, por exemplo, com a etnologia indígena, essa área de preservação de temas e paradigmas clássicos da disciplina?

Decerto, a TAR aceita de muito bom grau o convite para tratar de situações em que os sujeitos indígenas se encontram imersos em relações de novo cunho. Pensemos em algo que envolva, por exemplo, sapos amazônicos, leis de 


\section{ENTREVISTA}

propriedade intelectual, xamanismo e laboratórios farmacêuticos; ou máscaras xinguanas, um castelo no vale do Loire e a comemoração de um célebre antropólogo francês. As conexões inesperadas florescem, desprendendo esse inconfundível aroma TAR. Mas se o escopo da pesquisa fosse algo com um aspecto mais "clássico", por exemplo, parentesco e xamanismo entre os $\mathrm{Y}$ ?

Cada vez é mais improvável que questões clássicas como essa se desenvolvam num cenário totalmente clássico, isto é, no recesso da aldeia. De fato, elas ultrapassam qualquer demarcação, havendo, nesse caso, uma agressão mágica vinculada a uma disputa entre parentes sendo tratada via celular com um parceiro que está na cidade. Os mil inconvenientes da telefonia se tornarão, então, signos de uma ação maléfica e, para enfrentá-los, quem sabe se o xamã não usará, junto aos saberes exclusivos de sua tradição, outros saberes que ele coletou na internet.

Se, porventura - imaginemos, por um momento, uma combinação aventurosa de circunstâncias: estrada e rio impraticáveis, sem pista de pouso e cobertura telefônica -, o pesquisador se deparasse, durante os meses de sua pesquisa, com uma aldeia mais isolada do que as aldeias chegaram a ser, mesmo nos bons velhos tempos? Se o pesquisador se encontrasse nessa situação celebrizada pelas descrições de Malinowski, recém-chegado numa praia, com a canoa varada na areia, um fundo de palmeiras e os nativos olhando-o com curiosidade desde as suas casas; se tudo o que o pesquisador chegasse a contemplar estivesse contido nessa unidade de espaço, tempo e ação definida pela sua permanência na aldeia, ele poderia ainda se beneficiar da TAR?

Sem dúvida, sim. Sabemos, pelo menos desde Thomas Kuhn, que as novas teorias surgem sempre em combinação com novos objetos e novos métodos. Porém, seria contrário aos instintos de qualquer paradigma se restringir aos novos objetos que o trouxeram à tona, deixando os velhos em mãos das teorias que ele veio a desafiar, refutar ou pelo menos substituir.

Desse modo, a TAR, mesmo nessa situação malinowskiana antes evocada, abriria interessantes possibilidades. Em lugar de descrevermos um "grupo" de parentes e afins, poderíamos nos referir a uma rede, às condições em que ela é tecida, aos critérios que se usam para cortá-la. Isso seria bom: não reclamamos há tanto tempo, os etnólogos, da inadequada solidez de conceitos como sociedade e 


\section{ENTREVISTA}

grupo étnico, não ficamos advertindo o leitor de que, quando os usamos, estes devem ser entendidos num sentido fluido, performativo, transformacional, processual?

Em vez de tentarmos descrever coisas como a cosmologia dos $Y$, seu sistema de parentesco, sua moralidade - dedicando depois um bom tempo a ressalvar que há uma considerável variação desses esquemas dentro do grupo -, poderíamos apresentar, de um modo mais direto, aquilo que esse ou aquele nativo (mediadores, no sentido latouriano) elaboram a respeito do cosmos, das relações de parentesco ou da moral. Mediadores distintos elaboram diferentemente, de modo que nosso labor como etnógrafos consiste em mostrar quais são as relações que se estabelecem entre uns e outros, e não em procurar motivos para escolher entre essas expressões aquela mais representativa, mais coerente com a prática comum (?), mais legítima, ou mais tradicional.

Em lugar de elogiarmos a capacidade nativa de fagocitar culturas outras e reelaborá-las de acordo com vetores tradicionais, bem como de nos esforçarmos em demonstrar que índios ou brasileiros não deixam de ser índios ou brasileiros por falar inglês, usar celular ou fazer ioga, poderíamos adotar essa ideia, provocadoramente pop, porém instigante, da cultura como um plug-in, não menos eficaz por ser amplamente substituível.

Em vez de cairmos nesse tipo de trocadilho que nós profissionais da antropologia produzimos em série quando se trata de descrever as relações entre modelos e práticas (fatores do tipo: "recriam, tecem, conformam, ilustram enquanto são recriados, tecidos, conformados, ilustrados"), bem como de decidirmos se é melhor entender que o modelo paira nas alturas como um guia nunca totalmente atingido ou rasteja por baixo da prática como um padrão jamais plenamente consciente, poderíamos falar de tudo isso de um modo fiel à nossa experiência, ou seja, poderíamos falar da prática de criar modelos, propondo-os e impondo-os.

Enfim, em lugar de sacrificarmos a nossa pesquisa nos altares de uma teoria que em geral se mostra indiferente à fumaça dessa oferenda, poderíamos colocá-la, mais crua, ao lado dela, e a nós mesmos, com a nossa capacidade de mediação, entre ambas.

No entanto, há alguns fatores que se opõem a todas essas possibilidades. As objeções que a TAR apresenta aos conceitos mais comuns da sociologia do social - 


\section{ENTREVISTA}

ou da antropologia do cultural - são objetos, nos domínios da etnologia, de uma espécie de moratória que permite que, enquanto questionamos os conceitos clássicos - sociedade ou cultura, sem ir mais longe - no cenário global, possamos dar-Ihes ainda curso legal nesse domínio concreto. Não é apenas possível, mas mesmo necessário, afirmar as sociedades indígenas como sociedades, mesmo que depois se acrescente essa caterva de adjetivos (fluidas, performativas, transformacionais). O contrário faria pensar, quiçá, naquela collubies gentium diagnosticada quase duzentos anos atrás por Von Martius. Tratar como plug-ins culturas em processo de patrimonialização - como é o caso não apenas das culturas indígenas, mas de tudo que pode ser rotulado como cultura no mundo atual - pode parecer frívolo. Nesse sentido, se a cultura e a sociedade globais podem se permitir ser frívolas, líquidas ou mesmo gasosas, os nativos que aspiram ao respeito de alguns direitos continuam obrigados, parece, a carregar nas costas sociedades e culturas de uma consistência paleoindustrial.

Quando tratamos do grande cenário planetário, buscamos o mediador e olhamos com certo menosprezo o intermediário, aquele que se limita a reproduzir, sem variações significativas, uma opinião e uma prática. No caso da etnologia, ainda parece haver um lugar para esse intermediário ideal, que transmite uma tradição como chamá-la, se palavras como "pura" ou "inalterada" foram banidas do vocabulário? -, enfim, para esse nativo, o qual acreditamos que não inventa atitude coerente com os projetos de patrimonialização antes citados.

Em boa medida, a etnologia trata de situações em que esses conceitos maltratados pela crítica atual foram providos de aspas, o que, para aquém de tudo aquilo que Manuela Carneiro da Cunha alegou para o caso da "cultura", significa que eles caíram sob a jurisdição de uma burocracia (o pode significar, também, profissionais da antropologia em funções públicas) que, em certa medida, os protege. São conceitos tombados, cuja permanência está garantida em determinados contextos.

Essa persistência da qual tratamos se enraíza também no vigor residual de um velho pressuposto. Costumamos dizer que o mundo contemporâneo, o nosso mundo, é já demasiado vasto e complexo para ser descrito nos termos das teorias clássicas. Afirmamos isso honrando a mais romântica das retóricas do progressismo, essa que apregoa a marcha avassaladora do tempo (cem anos atrás 


\section{ENTREVISTA}

era o trem da história, uma máquina poderosa e impossível de deter ou desviar), que continua em pleno vigor ou, talvez, em plena exasperação na época digital. Contudo, não há como afirmar isso sem supor que existe, por contraste, algum mundo suficientemente pequeno e simples para ser adequadamente descrito por eles, ainda. Esse ainda encerra uma perigosa expectativa em relação ao passado: a de que nele houve um tempo em que as sociedades eram plenamente coerentes, os códigos rigorosamente observados, os híbridos desconhecidos, as fronteiras imaculadas. Se já é insensato conceder isso ao passado, que dizer da pretensão de que ainda existam no presente situações assim preservadas?

Sabemos que a complexidade é função dos instrumentos de observação, não do objeto, o que foi já dito por um dos inspiradores da TAR, Gabriel Tarde: a simplicidade a olho nu de uma gota d'água desaparece tão logo a observamos no microscópio, para dar lugar a uma proliferação de corpúsculos, havendo sempre um microscópio mais potente que escancare a multiplicidade do que previamente se afigurara elementar. Cada ampliação e cada redução da escala supõem apenas a desativação de umas relações e a ativação de outras. Essa espécie de microscópio, que é a observação participante, é perfeitamente capaz de mostrar que a simplicidade e a homogeneidade da vida de uma aldeia são apenas uma ilusão. Desse modo, ou a TAR vale para todos, ou não vale para ninguém.

Jean Segata: A TAR não traz, efetivamente, tantas novidades às Ciências Sociais como juram os burburinhos recentes. Mesmo assim, uma certa aura paira sobre os escritos de Latour, que parecem ter algo a mais a dizer - algum segredo para iniciados. Seria essa incerteza o segredo guardado? O que mais te incomoda com a TAR ou afinal, qual é a sua novidade?

Oscar Calavia Sáez: A outra coisa que me incomoda, na verdade uma variante da primeira, é a ênfase no aspecto inovador da própria TAR - teoria nova, até mesmo teoria revolucionária. Os textos da TAR, especialmente os de Bruno Latour, são pródigos em afirmações surpreendentes que desafiam alguns pressupostos clássicos e, às vezes, até mesmo o senso comum, de modo que não é estranho que seus seguidores sintam-se palmilhando esse universo novo, antes citado com sapatos igualmente novos. 


\section{ENTREVISTA}

Além disso, não é de se estranhar que entre os argumentos dos seus críticos destaque-se a vontade de mostrar que a TAR não é assim tão nova. Conforme se reconhece, mais do que tributária de autores como Tarde ou Garfinkel, ela é no fundamental uma reedição desses autores, ou do que eles têm de mais nominalista, antirracionalista, atomista etc.

Não exageremos. Negar novidade às propostas da TAR somente faz sentido para quem tem uma expectativa exagerada sobre a novidade das novas teorias. Para quem está disposto a esquecer que um dos principais efeitos de qualquer teoria nova é evocar os espíritos de uma longa linhagem de precursores, não se conforma com uma mínima recomposição dessa linhagem, alguma conexão inesperada e uma ampliação modesta do campo que dominam. Na verdade, nenhuma teoria inaugura uma Nova Era. Essa condição de origem de um novo tempo, tão improvável, é negada com razão às teorias dos desafetos e, com uma sem-razão inversamente proporcional, predicada das teorias mais caras. Isso é muito humano. Mas então, se assim for, por que se incomodar com a ênfase neotécnica na TAR? Muito simples: a TAR tem uma série de capacidades que correm sério risco de ser desaproveitadas caso nos deixemos encantar pelo seu brilho de paradigma novo em folha.

Nas ciências exatas ou naturais, os paradigmas se sucedem contundentes, porém parcimoniosamente. A biologia continua a ser basicamente darwiniana e a física, einsteiniana, com heterodoxia quântica e tentativas de conciliar ambas. No período que vai de Darwin ou da formulação da teoria de Einstein até a atualidade, cabe praticamente toda a história do que reconhecemos como ciências sociais, com uma enxurrada de paradigmas cuja exposição exige, nos cursos respectivos, três, quatro ou até cinco disciplinas semestrais pletóricas de bibliografia. O campo das ciências humanas pode parecer ao observador externo um coliseu romano onde as teorias triunfam e caem como gladiadores, entidades em situação de risco que apenas vivem o suficiente para estabelecer sua hegemonia pouco antes de sucumbir a mãos de um concorrente, ou, em termos menos climáticos, a mãos de sua obsolescência programada.

Essa diferença é acorde com os diferentes modos de produção de umas e outras ciências. A física ou a genética baseiam as suas grandes teorias em evidências e protocolos que estão fora do alcance da maioria da população. São 


\section{ENTREVISTA}

raríssimos os cidadãos capazes de enunciar essas teorias de um modo que não incorra, não digo, em imprecisões, mas em equívocos essenciais. Mas nada importa: na clínica, no avião ou na loja da Apple, encontramos, supõe-se, as provas fidedignas do valor das ciências, em forma de recursos técnicos que, segundo uma doutrina tácita e assim irrefutável, são tributários delas.

As ciências naturais e exatas agem como uma espécie de Deus bíblico de poder imenso e desígnios incompreensíveis, governando as nossas ações mesmo que não possamos perceber seu modo de operar.

As teorias das ciências humanas, pelo contrário, levam essa vida bem mais modesta dos deuses pagãos: elas existem no mesmo plano dos fenômenos que estudam. Andam na rua. São formuladas numa linguagem natural e, por isso, constantemente desafiadas pelo público. Dificilmente, um cidadão questionará a degradação de Plutão ou o DNA. Porém, nada impedirá que opine contra ou a favor, digamos, das teorias do tipo nature/nurture. Cada qual é capaz de alinhar suas experiências com alguma das grandes teorias em vigor nas ciências humanas, bem como de opinar, a partir dessa base, se a conduta sexual é instintiva ou aprendida, se as identidades étnicas são essenciais ou inventadas, se o poder político é fruto de um contrato ou de uma imposição, se as crises econômicas são erros estratégicos ou fenômenos estruturais. A opinião do leigo pode se basear em informação precária e se enunciar em termos pouco refinados, mas, mesmo assim, diferentemente do que acontece no setor das exatas/naturais, costuma haver uma coincidência no âmago entre a versão folk e a erudita, por muitas divergências de detalhe ou de matiz que existam. De fato, a vox populi pode ser citada como uma fonte de legitimidade no discurso erudito, enquanto o público usa as teorias das ciências humanas mais como bandeiras do que como leis. Por esse motivo, é raro que essas teorias optem por ser discretas: sua relevância depende em maior medida do favor do público, o que é um bom motivo para que os manifestos se divulguem mais do que os estudos realizados a partir deles.

Afinal, para que servem as ciências humanas? Um desafeto poderia objetar que para nada ou quase nada. Elas, longe de ajudarem na tomada de consciência ou de decisões, apenas multiplicam os dados já excessivos que temos a respeito do nosso ambiente, tornando intratável o que já era muito complexo e agindo, mais que como um instrumento, como um impedimento para a ação. 


\section{ENTREVISTA}

Muito se falou, por exemplo, sobre a colaboração entre a antropologia britânica e a empresa colonial: o etnógrafo em campo poderia ser um espião que ilustrasse a metrópole sobre os secretos mecanismos da vida dos outros, sobre os seus pontos fracos e fortes, sobre as brechas nas suas defesas, dando claves, enfim, para a conquista física e espiritual. No entanto, tudo parece indicar que a empresa colonial, longe de tirar proveito dos estudos minuciosos dos antropólogos do IAI, assumiu os grandes esquemas evolutivos dos velhos antropólogos "de gabinete" - justificativas de uma ação já previamente desenhada.

Seria frívolo descartar que a antropologia possa servir como instrumento de ação mais que como justificação, mas a experiência de qualquer um que lide com essa possibilidade sabe que não abundam as agências o bastante ágeis como para se beneficiar dessa possibilidade. Um século depois dessa experiência colonial citada, o que os órgãos públicos esperam das ciências sociais costuma ser um conjunto enxuto de lemas e juízos, sendo raro que demonstrem algo mais que impaciência perante uma pesquisa cheia de nuances, poréns, desconstruções e incertezas. Nas revoluções científicas das ciências humanas, parece faltar precisamente esse momento menos revolucionário de todos, qual seja: sua transformação em ciência normal; esse momento em que os princípios deixam de ser proclamados para ser postos em prática regularmente. Talvez não falte, mas, muito pelo contrário, sobre - e sobre sempre. Os sujeitos, incluindo as burocracias, têm projetos vinculados a uma trajetória própria, sendo difícil que os alterem atendendo aos ditames de uma ciência externa. Porém, isso não impede que apreciem formulações novas capazes de revigorar uma retórica já gasta. Ou seja, corrigindo parcialmente o que foi antes dito, os paradigmas das ciências humanas se normalizam, sim, mas muito menos no nível das descrições que produzem do que no nível dos manifestos que lançam - se normalizam como consignas. $O$ incômodo com a novidade que se enunciava no início dessa seção não se refere à novidade em si, mas a esse tipo de novidade que, parafraseando a frase impecável de Lampedusa, ajuda a que tudo fique o mais igual possível.

Pode se normalizar a TAR? Bruno Latour insiste repetidamente em que sua proposta é simples. Creio que boa parte dos seus leitores entende isso como um artifício retórico, destinado apenas a realçar a sofisticação daquilo que é apresentado como simples, quase simplório, plano. Um dos fragmentos mais 


\section{ENTREVISTA}

notáveis de Reassembling the Social consiste num diálogo hipotético entre o autor e um jovem estudante que confessa a Latour que não entendeu a sua proposta. $O$ autor responde as suas dúvidas num tom que parece conotar algo assim como: "quanto mal a academia pode fazer às jovens mentes, tornando-as inaptas para o mais fácil". Mas se o diálogo fosse outro? Por exemplo, entre o autor e um leitor que pensa ter entendido tudo e apenas quer conferir com o autor se, de fato, é simplesmente isso?

De fato, é o meu caso. Depois de ter lido o livro-manifesto de Latour com a impressão de tê-lo entendido sem dificuldades - na primeira parte deste artigo podem se encontrar as linhas gerais da minha leitura -, pude ler comentários a seu respeito que me fizeram pensar se a minha compreensão inicial não teria sido ilusória. Conceitos como "rede", "mediador" ou "descrição plana" encerrariam complexidades difíceis de desentranhar sem um estudo cuidadoso e auxiliado por um conhecimento profundo de teorias subsidiárias? Estariam muito longe dessa autodefinição intuitiva que sugerem a primeira vista? O objeto e o quase-objeto são objetos, junto com cada um dos outros itens do vocabulário da TAR, de uma exegese imponente cujo efeito final é semelhante ao da filmagem do Hobbit, de Peter Jackson, numa velocidade de 48 quadros por segundo com o uso simultâneo de duas câmeras e um espelho: uma vertiginosa imobilidade.

Será que estou de fato iludido, ou haveria aqui uma espécie de hermenêutica reversa, destinada a reformular em termos adequadamente críticos um discurso de desoladora claridade?

Não sei o que o próprio Latour julga disso, mas a impenetrabilidade tem sido moeda forte na tradição acadêmica. Malgrado tudo que possa ser dito em contra da gíria acadêmica, ela não carece de alguma dignidade, pois cumpre algumas funções básicas, como a de regular o acesso e o uso do conhecimento, evitando, por exemplo, que os pacientes se automediquem ou que análises matizadas se transformem em manchetes sensacionalistas. O tempo e a paciência, necessários para desentranhar a complexidade das palavras, são úteis para que o iniciante tome consciência também da complexidade das coisas e para desencorajar os irresponsáveis. Há outro valor mais sutil: os enigmas incentivam a atividade intelectual, é mais fácil - e mais sedutor - seguir princípios que não se compreendem totalmente. Explanações muito claras de qualquer questão, 


\section{ENTREVISTA}

paradoxalmente, tendem a tornar invisíveis as suas saliências, suas novidades. Uma terminologia difícil pode equivaler a um bom sistema de acentuação gráfica, sempre que não cresça até ocultar o texto.

Apesar do grande sucesso da TAR no quesito de inovação léxica, creio que o seu interesse reside mais nos aspectos em que ela não é exatamente uma teoria. Nesse sentido, sigo Latour, que em Reassembling the Social expõe suas dúvidas sobre o termo teoria (como as expõe a respeito dos conceitos de "ator" e "rede") e prodiga todo tipo de alegorias tácteis (a das formigas é a principal) para a sua proposta. Ora, tatear, avançar por tentativa e erro, situa essa proposta nas antípodas da "teoria", ligada desde as suas raízes etimológicas à visão, à contemplação panorâmica.

Tentativa e erro: eis aqui que a segunda seção do meu escrito se volta para a primeira. Pensar a TAR como um recurso que pode se aplicar a objetos de estudo clássicos não é apenas reivindicar um complemento de relevância, o que seria irrelevante ("bom, sim, tá certo, poderia se fazer TAR também numa ilha ilhada... se por acaso for capaz de encontrar tal coisa"), mas também, muito mais, colocar a TAR num cenário onde se torna visível a sua filiação não com a etnografia tradicional, mas com a autocrítica que essa etnografia gerou ao longo de sua existência, com a história das suas tentativas e os seus erros. A TAR é, na opinião de quem subscreve, o resultado do cruzamento entre o legado etnográfico dos séculos passados e essa recapitulação reflexiva que ocupou a antropologia durante os últimos decênios do último século. Digo recapitulação porque - em que pese às aspirações dos pós-modernos a inaugurar uma nova era - reflexão e autocrítica, mais ou menos agudas, mais ou menos consequentes, nunca faltaram no trabalho dos seus melhores expoentes. O mérito principal da antropologia crítica foi o de sistematizar esses pontos: a relação entre o nativo e o antropólogo e a imprevista ou indesejada realidade deste no campo que alguma vez sonhou poder contemplar desde 0 ar. A autoria dos nativos, que nunca são simples transmissores ("intermediários") de uma cultura ou uma sociedade, mas criadores desta, recorre a todos os instrumentos que se lhe oferecem, entre eles, as próprias ideias e perguntas do pesquisador, a incerteza que supera leis e padrões, a evanescência de todas as figuras da totalidade - sociedade, cultura, indivíduo. Depois de alguns decênios colocando na nossa prateleira livros sobre a invenção disso e a construção 


\section{ENTREVISTA}

daquilo, que transformam o nosso solo léxico tradicional num campo minado, o que resta da trajetória da antropologia é uma série de redes que a pesquisa tem tecido entre sujeitos emissores ou receptores (os nativos, o público, os burocratas, os outros pesquisadores) e instituições, teorias, técnicas e objetos. Isso não é uma revelação súbita que põe em questão a sociologia do social ou a antropologia do cultural, mas fruto da autoconsciência crítica da pesquisa que as construiu.

$\mathrm{Na}$ TAR, mais do que o confronto com teorias anteriores, há uma espécie de desvio de finalidade; mais do que uma virada, há uma guinada. Trata-se de uma guinada pragmática, cujas linhas gerais são todos os dias recitadas nas salas das universidades, nessas sessões que os orientadores (ou pelo menos um importante segmento deles) dedicam aos seus orientandos. A descrição etnográfica é o mais valioso. Os dados nunca são simples dados, pois embutem invenção, reflexão, especulação. A etnografia se escreve, e o texto não é nunca um simples intermediário das ideias. A teoria deve orientar a pesquisa, não dirigi-la, muito menos enquadrá-la. Tem um sem-fim de conselhos destinados a convencer 0 ouvinte de que o valor maior de sua pesquisa estará na interação com o seu campo, e não na execução inspirada de alguma ária doutrinal. Trata-se de missão árdua, porque dificilmente é acompanhada do exemplo: enquanto os orientadores mandam a seus alunos que descrevam, eles teorizam, e mesmo se o fazem é apenas porque não têm tempo para outras coisas mais difíceis, resta essa mensagem subliminal: em baixo a descrição, em cima a teoria.

É precisamente essa diferença de níveis o alvo principal das críticas TARianas: a primazia de algum tipo de destilado ("o social") sobre a descrição, sobre o traçado de redes, é parte da economia política da academia. Como demonstra a recepção da TAR nos meios acadêmicos - demasiado voltada, como dissemos, para uma sobre-exposição escolástica dos seus conceitos -, não é fácil que esse quadro mude. Porém, a TAR é, quando menos, uma tentativa astuta de recomendar esse levantamento de redes como proposta vanguardista e não - ao estilo do professor cansado dos ismos - como uma ressaca de vanguardas que já consumiram o seu potencial de sedução.

A TAR inclui certamente, além dessa guinada, um manifesto ou uma bandeira compatíveis com o que tem sido chamado de virada ontológica. Sem entrar no argumento desta, refiro-me apenas ao que considero seu principal corolário político. 


\section{ENTREVISTA}

Se há um campo em que as ciências humanas são politicamente relevantes, hoje em dia, não é o da teoria, mas o da descrição, pela simples razão de que, num universo de livre hipercirculação das teorias, o lugar da realidade é controlado por meio de uma insistente e monótona descrição. Isso é, afinal, o multiculturalismo: que floresçam mil culturas e mil escolas de pensamento enquanto permaneça aí algo uma natureza, ou uma realidade nua e crua - a confiná-las. Desafiem-se à vontade as ortodoxias, desconstruam-se a bel-prazer todos os constructos: o poder não mais se preocupa em sustentar doutrinas, apenas, como um feitor bem-educado, apela à realidade: a do mercado, a das urnas, a das necessidades prementes da população. Essa realidade, que em si não tem nada de óbvio - pensemos na expectativa do crescimento perpetuamente sustentado -, não se faz nem se desfaz com fórmulas, mas com descrições e narrações por extenso, que acabam por torná-la verossímil e fonte de verossimilhança. Não há nenhuma jogada magistral que desvende o engano, até porque já sabemos de sobra que não existe verdade nua e crua à espera de ser despida, mas um relato poderoso que somente pode ser substituído por outro que o supere. A principal novidade da TAR não está nos seus conceitos, mas no seu postulado de que, nesse universo aparentemente saturado de informação, quase tudo está ainda por descrever. 